\title{
The Multiple Waves of Cannabinoid 1 Receptor Signaling
}

\author{
Carlos Nogueras-Ortiz and Guillermo A. Yudowski \\ Institute of Neurobiology(C.N.-O., G.A.Y.) and Department of Anatomy and Neurobiology (G.A.Y.), University of Puerto Rico \\ Medical Sciences Campus, San Juan, Puerto Rico
}

Received April 1, 2016; accepted June 22, 2016

\section{ABSTRACT}

The cannabinoid 1 receptor $\left(\mathrm{CB}_{1} \mathrm{R}\right)$ is one of the most abundant G protein-coupled receptors (GPCRs) in the central nervous system, with key roles during neurotransmitter release and synaptic plasticity. Upon ligand activation, $\mathrm{CB}_{1} \mathrm{Rs}$ may signal in three different spatiotemporal waves. The first wave, which is transient ( $<10$ minutes) and initiated by heterotrimeric $\mathrm{G}$ proteins, is followed by a second wave ( $>5$ minutes) that is mediated by $\beta$-arrestins. The third and final wave occurs at intracellular compartments and could be elicited by $\mathrm{G}$ proteins or $\beta$-arrestins. This complexity presents multiple challenges, including the correct classification of receptor ligands, the identification of the signaling pathways regulated by each wave, and the underlying molecular mechanisms and physiologic impacts of these waves. Simultaneously, it provides new opportunities to harness the therapeutic potential of the cannabinoid system and other GPCRs. Over the last several years, we have significantly expanded our understanding of the mechanisms and pathways downstream from the $C B_{1} R$. The identification of receptor mutations that can bias signaling to specific pathways and the use of siRNA technology have been key tools to identifying which signaling cascades are controlled by $\mathrm{G}$ proteins or $\beta$-arrestins. Here, we review our current knowledge on $\mathrm{CB}_{1} \mathrm{R}$ signaling, with particular emphasis on the mechanisms and cascades mediated by $\beta$-arrestins downstream from the $\mathrm{CB}_{1} \mathrm{R}$.

\section{Introduction}

Functional selectivity, also called ligand or receptor bias, is the ability of ligands to activate a subset of the full repertoire of signaling cascades available to individual G proteincoupled receptors (GPCRs) (Urban et al., 2007). This concept, based on numerous analytical observations from different laboratories, challenged our classic definition of a ligand's intrinsic efficacy (i.e., the property of a ligand/receptor pair to elicit the full set of biologic responses). Functional selectivity also provided a novel conceptual framework and therapeutic opportunities to pharmacologically control GPCR function (Ariens, 1954; Kenakin, 2004), which resulted in the realization that signaling from individual GPCRs is even more complex than initially proposed and that receptor signaling is in fact pluridimensional (Galandrin et al., 2007; Kenakin, 2011; Luttrell, 2014). Elucidation of GPCR pluridimensionality has led to the rational search for more effective therapeutic agents and the systematic exploration of the signaling

This work was supported by the following research grants from the National Institutes of Health to G.A.Y. and C.N.O. [Grants DA023444 and R01DA037924]; G.A.Y and F.D.P. G.A.Y received further support from the Puerto Rico Science Trust.

dx.doi.org/10.1124/mol.116.104539. pathways and molecular mechanisms underlying functional selectivity. With the ability to specifically abrogate desired proteins, either genetically or chemically, while analyzing downstream effectors, our current knowledge of these events has increased exponentially; however, we are still far from having a complete picture of the events that follow GPCR activation that lead to biologic responses. Assisted by the development of powerful computational tools for structure/function analysis, additional relevant pieces of this intricate jigsaw puzzle are realized almost daily with the continuous description of GPCR crystal structures and their associated proteins (Katritch et al., 2013; Maudsley et al., 2013; Johnston and Filizola, 2014; Shukla et al., 2014a).

In this review, we discuss functional selectivity of the cannabinoid 1 receptor $\left(\mathrm{CB}_{1} \mathrm{R}\right)$, one of the most highly expressed GPCRs in the central nervous system. First, we review the different signaling waves characterizing functional selectivity of the $\mathrm{CB}_{1} \mathrm{R}$ that are mediated by $\mathrm{G}$ proteins and $\beta$-arrestins. Then we focus the discussion on ligand bias toward $\beta$-arrestins and the underlying molecular mechanisms. We discuss the in vivo data from wild-type, knockout, and knock-in mice and conclude by highlighting intriguing problems and suggesting areas where further research is

ABBREVIATIONS: AEA, anandamide; $\mathrm{CB}_{1} \mathrm{R}$, cannabinoid 1 receptor; $\mathrm{CP}, \mathrm{CP} 55,940$; $\mathrm{CREB}$, cAMP response element-binding protein; $\triangle 9$-THC, $\triangle 9$-tetrahydrocannabinol; ERK1/2, extracellular signal-regulated protein kinases 1 and 2; GPCRs, G protein-coupled receptors; GRK, G proteincoupled receptor kinases; JNK, c-Jun N-terminal kinase; p38a, mitogen-activated protein kinase 14; PTX, pertussis toxin; Src, SRC protooncogene, nonreceptor tyrosine kinase; 2-AG, 2-arachidonoylglycerol; WIN, WIN55,212-2. 
needed to understand the physiologic roles and therapeutic potential of $\beta$-arrestin-mediated signaling of the $\mathrm{CB}_{1} \mathrm{R}$.

The $\mathrm{CB}_{1} \mathrm{R}$ is one of the most abundant GPCRs in the central nervous system, with expression levels ranging between 0.5 and $7 \mathrm{pmol} / \mathrm{mg}$ protein in numerous areas of the rat brain (Herkenham et al., 1991; Mackie, 2008; Marsicano and Kuner, 2008). $\mathrm{CB}_{1} \mathrm{R}$ localization in neuronal cells is highly polarized to axons and presynaptic sites, where they control synaptic neurotransmitter release and neuronal function (Howlett et al., 1990; Mackie, 2008; Castillo et al., 2012). They are activated by their endogenous ligands (endocannabinoids), such as anandamide and 2-arachidonyl glycerol (2-AG), and they are also activated by tetrahydrocannabinol ( $\Delta^{9}$-THC), the main psychoactive ingredient in marijuana, that has been linked to multiple physiopathological conditions. The pharmacologic regulation of the $C_{1} R$ has been proposed as a therapeutic strategy for many neuropsychiatric disorders ranging from anxiety and stress to neurodegenerative disease and epilepsy (Howlett et al., 2002; Howlett, 2005; Mackie, 2006; Lutz et al., 2015).

\section{$\mathrm{CB}_{1}$ Receptor Signals in Three Different Waves}

Biochemical analysis indicates that $\mathrm{CB}_{1} \mathrm{Rs}$, like multiple other GPCRs, such as angiotensin type 1 receptor and type 1 parathyroid hormone-related protein receptor, can signal in three distinct spatiotemporal waves (Luttrell and Gesty-Palmer, 2010; Lohse and Calebiro, 2013). An initial wave mediated by heterotrimeric $\mathrm{G} \alpha_{\mathrm{i} / \mathrm{o}}$ proteins begins after ligands bind receptors at the plasma membrane, leading to a rapid decrease in cAMP levels, a decrease in $\mathrm{Ca}^{2+}$ conductance, and an increase in $\mathrm{K}^{+}$ conductance (Fig. 1) (Howlett et al., 2004). $\mathrm{CB}_{1} \mathrm{Rs}$ present significant functional selectivity at the $\mathrm{G}$ protein level. $\mathrm{CB}_{1} \mathrm{Rs}$ couple mainly to heterotrimeric $\mathrm{G}_{\mathrm{i} / \mathrm{o}}$ but also to other $\mathrm{G}$ proteins (Glass and Northup, 1999; Varga et al., 2008; Bosier et al., 2010). This promiscuity has been extensively characterized utilizing in vitro assays in different cell lines, further emphasizing the generalized notion that the cellular environment is highly relevant during $\mathrm{CB}_{1} \mathrm{R}$ signaling; careful consideration must be taken when interpreting results obtained from heterologous systems where different protein levels of receptor/signaling molecules can have a profound effect on their function (Bosier et al., 2010; Atwood et al., 2011; Straiker et al., 2012).

Ligand-induced receptor phosphorylation results in receptor desensitization and the recruitment of the scaffold $\beta$-arrestins (Jin et al., 1999; Kouznetsova et al., 2002). $\beta$-arrestins, while hindering G-protein signaling, act as scaffold proteins for the endocytic machinery and signaling molecules such as the mitogen-activated protein family of kinases and initiate the second wave of signaling at the cell surface (Ahn et al., 2013; Flores-Otero et al., 2014). This review focuses on this wave and the mechanisms underlying these events below.

A final third wave emerges from receptors localized at intracellular compartments, such as endosomes and lysosomes. Native $\mathrm{CB}_{1} \mathrm{Rs}_{\mathrm{s}}$ are particularly enriched at intracellular compartments in Neuro2A cells and primary hippocampal cultures when analyzed by immunostaining and discontinuous sucrose gradients (Rozenfeld and Devi, 2008). By combining the lipophilic agonist WIN-55212-2 [(11R)-2-methyl-11-(morpholin4-ylmethyl)-3-[(naphthalen-1-yl)carbonyl]-9-oxa-1-azatricyclo [6.3.1. $\left.0^{\wedge}\{4,12\}\right]$ dodeca-2,4,6,8(12)-tetraene] with the receptor blocker peptide hemopressin, which does not cross the plasma membrane, signaling from intracellular native receptors was shown to stimulate extracellular signal-regulated protein kinase (ERK) phosphorylation in Neuro2A cells. Indirect support of intracellular signaling was further presented by coimmunoprecipitation of $\mathrm{G}$ proteins and $\mathrm{CB}_{1} \mathrm{Rs}_{\mathrm{s}}$ from endosomal compartments isolated from these cells (Rozenfeld and Devi, 2008). More recently, calcium release from intracellular stores was demonstrated by injecting ananadamide into human embryonic kidney cells transfected with $\mathrm{CB}_{1} \mathrm{Rs}$, further suggesting a signaling wave from receptors localized in intracellular compartments (Brailoiu et al., 2011). Careful consideration should be taken, however, when analyzing receptor signaling and trafficking, particularly when comparing heterologous systems, different cellular models, and ligands at saturating or high concentrations. When trying to understand receptor function, factors that should be taken into consideration include differences in receptor and accessory protein expression levels, their cellular localization, ligand bias, and ligand on/off rates among others.

Are these signaling waves relevant in vivo? What are their possible biologic roles? Are they present in some, but not all, cells? We are at the beginning of a new era of GPCR pharmacology, and these questions must be addressed to help the rational design of new and improved therapeutics.

\section{Multifaceted $\boldsymbol{\beta}$-Arrestins}

Four highly homologous $\beta$-arrestin isoforms have been described in mammals. Arrestin 1 and arrestin 4 (visual arrestins) are expressed only in the retina, and arrestin 2 and 3 (referred in this review as $\beta$-arrestin 1 and $\beta$-arrestin 2 , respectively) are expressed ubiquitously (Gainetdinov et al., 2004; Gurevich and Gurevich, 2006; Premont and Gainetdinov, 2007). $\beta$-arrestins were initially identified in the late $1980 \mathrm{~s}$ and early 1990s as key proteins during the inactivation or "arrest" of ligand activated GPCRs (Pfister et al., 1985; Benovic et al., 1987; Lohse et al., 1990; Schmid and Bohn, 2009 ), and a second critical role for $\beta$-arrestins during the ligand-induced receptor internalization was discovered soon after. The $\beta$-arrestin $\mathrm{C}$ terminus binds directly to clathrin and the adaptor protein 2 , thus working as a scaffold for the endocytic machinery leading to the removal of desensitized receptors from the cell surface via clathrin-mediated endocytosis (Goodman et al., 1996; Laporte et al., 1999). More recently, a third function was described; $\beta$-arrestin recruitment to phosphorylated receptors initiates a $\mathrm{G}$ proteinindependent wave of signaling that results in the activation of multiple effectors including ERK, c-Jun N-terminal kinase (JNK), and SRC proto-oncogene nonreceptor tyrosine kinase (Src), among others (Gurevich and Gurevich, 2006; DeWire et al., 2007; Luttrell and Gesty-Palmer, 2010; Shenoy and Lefkowitz, 2011). Not surprisingly, $\beta$-arrestin function as signaling facilitator is specific and dependent on the type of receptor, ligand, and cellular environment (Whalen et al., 2011; Srivastava et al., 2015).

With the available crystal structures and computational modeling, we can outline the events characterizing the interaction between $\beta$-arrestins and activated receptors. It has been postulated that this interaction consists of two differential and sequential steps, initially between the receptor carboxy terminus and the $\mathrm{N}$ domain of $\beta$-arrestins and later between the receptor transmembrane core and different 


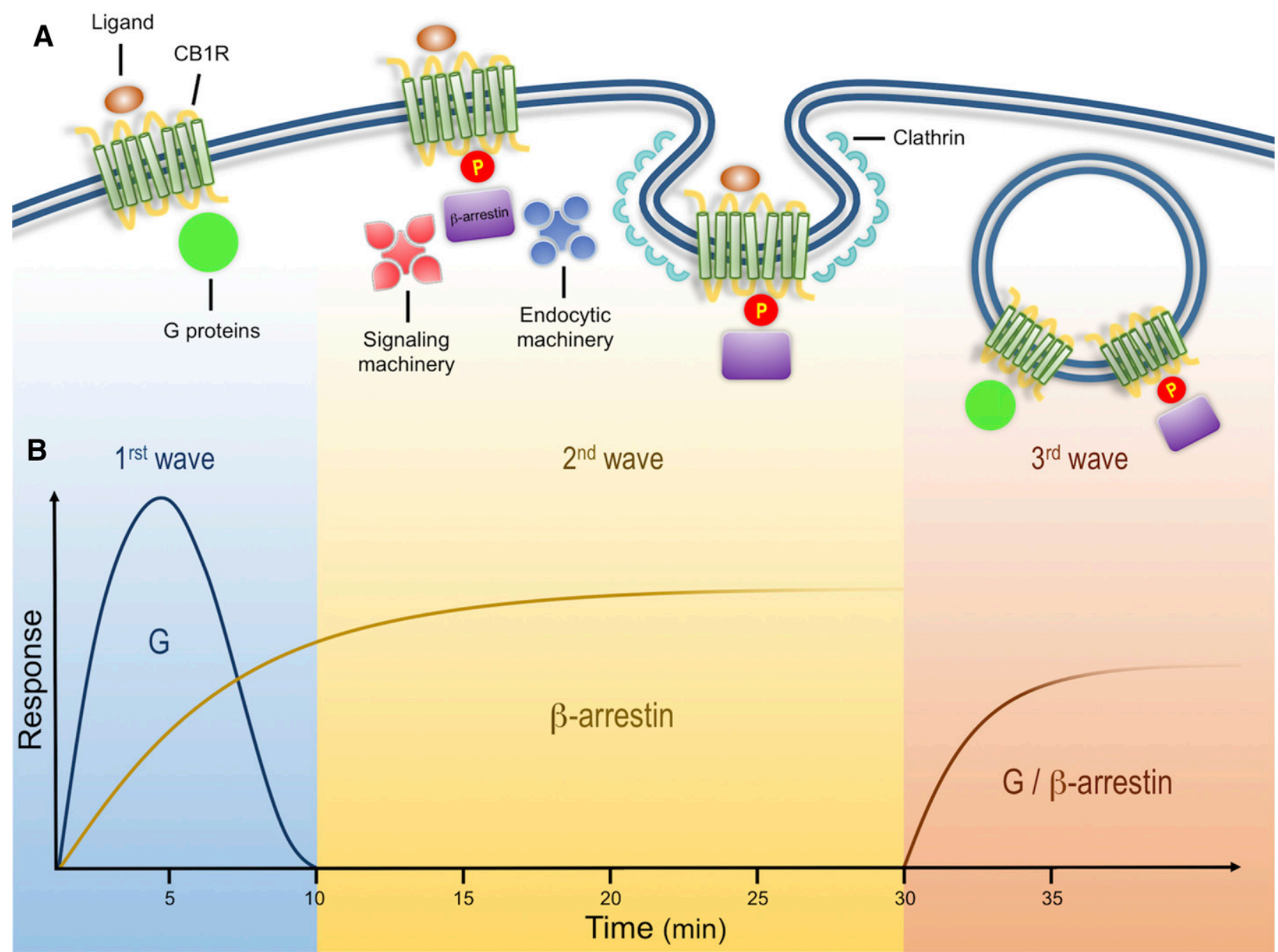

Fig. 1. Cannabinoid receptor signals in three waves. (A) Activation of $\mathrm{CB}_{1}$ Rs results in the modulation of multiple cellular responses through three distinct signaling waves. The first wave, mediated by G proteins, is observed within seconds and up to few minutes after receptor activation. Receptor activation also results in phosphorylation by GRKs. This post-translational modification leads to receptor desensitization and the recruitment of $\beta$-arrestins, scaffold proteins of the endocytic machinery that initiate clathrin-mediated endocytosis. In addition to the endocytic machinery, receptor bound $\beta$-arrestins can also recruit and activate signaling proteins, resulting in a second signaling wave with distinct kinetic and signaling profile. These events are initiated at the plasma membrane and can continue after receptor endocytosis into intracellular compartments. After receptor internalization, a third signaling wave has been described that is characterized by the activation of effectors associated with both $\mathrm{G}$ proteins and $\beta$-arrestins. (B) Proposed time course of $\mathrm{G}$ protein- and $\beta$-arrestin-mediated responses. $\mathrm{G}$ protein signaling has a fast initial response, whereas $\beta$-arrestins are somewhat slower but sustained over time. Kinetics of third waves can be initiated within minutes (modified from Luttrell and Gesty-Palmer, 2010).

surface areas at the concave region of $\beta$-arrestins (Gurevich and Gurevich, 2004; Shukla et al., 2014b; Kang et al., 2015). Receptor binding results in increased dynamics at the $\mathrm{N}$ and $\mathrm{C}$ domains of $\beta$-arrestins, and this likely affects their interaction with the endocytic and signaling machinery.

Among the possible signaling cascades available to GPCRs, those controlled by $\beta$-arrestins have been suggested as good candidates to mediate some of the beneficial effects attributed to current therapeutic compounds. For example, the Food and Drug Administration-approved $\beta$-blocker carvedilol (Warne et al., 2008; Tzingounis et al., 2010) and the agonist isoetharine (Drake et al., 2008; Liu et al., 2012) have different patterns of signaling among $\mathrm{G}$ protein and $\beta$-arrestin-mediated pathways. Interestingly, the antipsychotic drug aripiprazole is highly efficacious at activating signaling cascades mediated by $\beta$-arrestins from the dopamine 2 receptors, and this has led to a search for new dopaminergic antipsychotics with improved efficacy (Mailman, 2007; Allen et al., 2011; Urs et al.,
2014; Brust et al., 2015). Ligand bias toward $\beta$-arrestins has been implicated in several pathologic events, including cardiovascular disorders, pain responses, and some of the behavioral effects associated with cannabis use, which suggests that $\beta$-arrestin-mediated signaling components could be potential therapeutic targets (Breivogel et al., 2008; Whalen et al., 2011).

\section{$\mathrm{CB}_{1}$ Rs and $\beta$-Arrestin-Mediated Signaling}

In vivo, the role of $\beta$-arrestins as signaling molecules is somewhat elusive. Canonical functions of arrestins, including receptor desensitization, regulation of receptor sensitivity to acute agonists, and regulation of receptor internalization, have been reported (Breivogel et al., 2008; Whalen et al., 2011; Nguyen et al., 2012). $\beta$-arrestin 2 knockout mice displayed enhanced antinociceptive responses to acute $\Delta^{9}$-THC and decreased tolerance, similar to the enhanced antinociceptive 


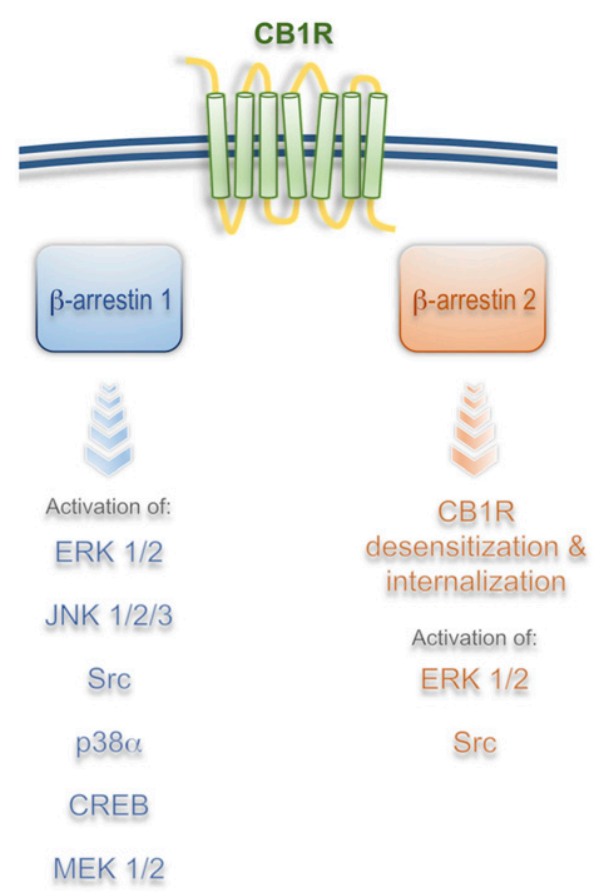

Fig. 2. $\beta$-Arrestin effectors downstream from $\mathrm{CB}_{1} \mathrm{R}$. Brief summary of published results utilizing different cellular and tissue models suggests that $\beta$-arrestin 1 mediates most of the signaling whereas $\beta$-arrestin 2 mediates receptor desensitization and internalization in vitro and in vivo. Signaling from $C_{1} R / \beta$-arrestin 1 results in regulation of gene transcription and protein synthesis, which suggests that long-term effects of $\mathrm{CB}_{1} \mathrm{R}$ activation are mediated by $\beta$-arrestins (see text for more detail).

action observed with opioids in the knockout animals, and more likely associated with reduced receptor desensitization and/or enhanced $\mathrm{G}$ protein signaling rather than $\beta$-arrestin mediated signaling (Bohn et al., 2000; Nguyen et al., 2012). Somewhat similar results were observed with a knock-in mice where the putative $\mathrm{CB}_{1} \mathrm{R}$ G protein-coupled receptor kinases (GRK) sites S426/430 were mutated to alanines (Morgan et al., 2014). These mice were more sensitive to acute $\Delta^{9}$-THC, present delayed tolerance, and have reduced receptor desensitization (Morgan et al., 2014). Interestingly, work on $\beta$-arrestin 1 knockout mice demonstrated a reduced ability of the full agonist CP 55,940, but not $\Delta^{9}$-THC, to induce antinociception and hypothermia, suggesting either a signaling role of $\beta$-arrestin 1 or compensatory actions of $\beta$-arrestin 2 on CB1 receptors. These data provide new support to the divergent roles of $\beta$-arrestin 1-2 in vivo and suggest that $\beta$-arrestin 1 regulates receptor sensitivity in an agonist-dependent manner with no significant effect on the regulation of cannabinoid tolerance (Breivogel and Vaghela, 2015). Substantial effort should be devoted to further distinguish desensitization versus signaling roles of $\beta$-arrestins in vivo, particularly for the development of biased therapeutics and for efforts directed toward unraveling $\beta$-arrestin function in vivo.

At the molecular level, it was initially suggested that $G$ protein-independent signaling from the $\mathrm{CB}_{1} \mathrm{R}$ was a possible mechanism for the activation of certain kinases and for the regulation of gene transcription (Jin et al., 1999; Bosier et al., 2008; Daigle et al., 2008; Ahn et al., 2012). Activation of pertussis toxin-insensitive signaling cascades from the $\mathrm{CB}_{1} \mathrm{R}$ by the ago-allosteric modulator Org27569 (5-chloro-3-ethyl-N[2-(4-piperidin-1-ylphenyl)ethyl]-1H-indole-2-carboxamide) was demonstrated in hippocampal neurons endogenously expressing $\mathrm{CB}_{1} \mathrm{Rs}$ (Ahn et al., 2012; Baillie et al., 2013). $\beta$-arrestinmediated signaling downstream from the $\mathrm{CB}_{1} \mathrm{R}$ was first unequivocally demonstrated in human embryonic kidney cell line HEK293 using a combination of $\beta$-arrestin $1 / 2$ siRNA and pertussis toxin treatment (Ahn et al., 2013). In these experiments, ORG27569 elicited strong ERK1/2, Src, and MEK1/2 phosphorylation that were reduced only by $\beta$-arrestin 1 siRNA (Ahn et al., 2013). Interestingly, $\beta$-arrestin 2 was not involved in the signaling process but in the internalization of the receptor, suggesting distinct roles for these molecules. The combination of pertussis toxin, dominant negative $\mathrm{G} \alpha_{\mathrm{i} / \mathrm{o}}$ minigenes, and $\mathrm{G} \beta \gamma$ scavenging peptides was later used by Mahavadi et al. (2014) to show that activation of $\mathrm{CB}_{1}$ receptor by anandamide (AEA) in cultured smooth muscle cells results in a GRK5/ $\beta$-arrestin $1 / 2$ time-dependent activation of ERK1/2 and Src. Interestingly, both $\beta$-arrestin 1 and 2 siRNA were effective at reducing ERK1/2 activity (Mahavadi et al., 2014). Differences in the roles of $\beta$-arrestin $1 / 2$ among studies are likely a result of different cell systems or different strategies used; however, overlapping, as well as divergent roles of $\beta$-arrestins, have been well documented in many cell models, receptors, and tissues (Srivastava et al., 2015) (Fig. 2).

Additional characterization of the effect of cannabinoids on the activation of kinases and the regulation of gene expression was investigated using a cell culture model of striatal medium spiny neurons STHdh ${ }^{\text {q7/q7 }}$ (Laprairie et al., 2014). In this study, BRET, FRET, and kinase phosphorylation analyses were used to characterize the functional selectivity of six different cannabinoid receptor ligands, including two endocannabinoids and $\Delta^{9}$-THC. 2-AG, $\Delta^{9}$-THC, and CP 55,940 induced a prolonged ERK activation dependent on $\beta$-arrestin 1, whereas Akt phosphorylation was mediated by G proteins upon incubation with 2-AG, AEA, and WIN (Laprairie et al., 2014). These results support the notion that functional selectivity of cannabinoid receptor ligands regulates kinase activity selectively. The authors examined whether receptor signaling bias also translates to gene expression using the $\mathrm{CB}_{1} \mathrm{R}$ as a target gene based on previous findings showing that $\mathrm{CB}_{1} \mathrm{R}$ mRNA levels are associated with Akt phosphorylation. Results showed that $1 \mu \mathrm{M}$ AEA, 2-AG, or WIN induced an increase in $\mathrm{CB}_{1}$ receptor mRNA levels via $\mathrm{G} \alpha_{\mathrm{i} / \mathrm{o}}$ proteins in association with the upstream activation of Akt (Laprairie et al., 2014). More recently, the same group reported that CP 55,940 and $\Delta^{9}$-THC preferentially enhanced the recruitment of $\beta$-arrestin 1 and reduced cellular viability in a cell model of Huntington disease, supporting the idea that cannabinoids with $\beta$-arrestin bias could be detrimental in Huntington disease models (Laprairie et al., 2016).

Recent work showed that 2-AG can induce prolonged (>10 minutes) phosphorylation of ERK1/2, JNK1/2/3, CREB, and $\mathrm{P} 38 \alpha$ via $\beta$-arrestin 1 within 5 minutes after ligand incubations (Delgado-Peraza et al., 2016). Interestingly, mutation of putative GRK phosphorylation sites S426/430A resulted in a $\beta$-arrestin-mediated signaling-biased receptor. $\mathrm{CB}_{1} \mathrm{R}$ S426/430A displayed reduced $\beta$-arrestin 2 recruitment, associated with a lower internalization rate, and normal $\beta$-arrestin 1 recruitment, which is linked to increased $\beta$-arrestin 1 -mediated signaling (Delgado-Peraza et al., 2016). This result supports the hypothesis that ligands induce specific receptor phosphorylation profiles that result in unique signaling cascades (Fig. 2). 


\section{Mechanism Controlling $\beta$-Arrestin-Mediated Signaling}

Upon ligand binding, GPCRs undergo conformational changes leading to the activation of heterotrimeric $\mathrm{G}$ proteins and their effector cascades. These changes in receptor conformation are detected by $\mathrm{G}$ protein-coupled receptor kinases (GRKs), resulting in specific phosphorylation patterns at receptor intracellular domains. Quantitative mass spectrometry approaches, combined with phosphospecific antibodies, have shown that ligand-induced receptor phosphorylation is tissue and ligand specific and can be associated with specific signaling cascades; this supports a phosphorylation barcode hypothesis (Butcher et al., 2011; Liggett, 2011; Nobles et al., 2011; Prihandoko et al., 2016). Receptor phosphorylation is recognized by $\beta$-arrestins, which are recruited to the plasma membrane and sterically hinder $\mathrm{G}$ protein association while initiating $\beta$-arrestin-mediated internalization and signaling (Nobles et al., 2011; Liggett, 2011). Data on the $\mathrm{CB}_{1} \mathrm{R}$ indicate that specific GRKs and phosphorylation sites at the receptor are necessary for $\beta$-arrestin-mediated signaling, further supporting the barcode model; however, how phosphorylated receptors transduce their activation into $\beta$-arrestin-mediated signaling was not defined until recently (Flores-Otero et al., 2014).

By directly visualizing individual $\mathrm{CB}_{1} \mathrm{R}$ endocytic events, the ligand modulation of endocytic dwell time, or the time receptors and $\beta$-arrestin cluster at the cell surface inside coated pits before their endocytosis was proposed to be a process that controls $\beta$-arrestin-mediated signaling (FloresOtero et al., 2014). Synthetic ligands, such as CP 55,940 or WIN, elicit short dwell times $(<120$ seconds) and little detectable $\beta$-arrestin 1 -mediated signaling, whereas $2-\mathrm{AG}$ elicits prolonged dwell times ( $>120$ seconds) and significant $\beta$-arrestin 1-mediated signaling (Flores-Otero et al., 2014). Supporting the correlation between dwell times and $\beta$-arrestin-mediated signaling, recent data show that $\beta$-arrestin-mediated signaling can be increased by inhibiting the internalization of receptors clustered into coated pits while prolonging their interaction with $\beta$-arrestins at the cell surface. Interestingly, $\mathrm{CB}_{1} \mathrm{R}$ endocytic dwell times are strictly dependent on the ligand and can be divided into either short $(<120$ seconds) or long $(>120$ seconds) dwell times. This differential response could be used to probe for ligands that promote $\beta$-arrestin-mediated signaling.

At the mechanistic level, this work showed that receptor prolonged dwell times are dependent on serines 426/430 (rat sequence conserved in human). Mutation of these sites resulted only in prolonged dwell times that triggered enhanced $\beta$-arrestin 1 -mediated signaling, reduced $\beta$-arrestin 2 recruitment, and decreased receptor internalization rates (Delgado-Peraza et al., 2016). As shown by immunoprecipitation, this interaction between the mutant receptor and $\beta$-arrestin 1 is enhanced and continues after internalization into intracellular compartments, a result that led to the use of the S426/430A mutant receptor as a tool to investigate $\beta$-arrestin-mediated signaling from the $\mathrm{CB}_{1}$ receptor. Data obtained from this receptor indicated that ERK1/2, JNK1/2/3, CREB, and $\mathrm{P} 38 \alpha$ are downstream from $\mathrm{CB}_{1} \mathrm{R} / \beta$-arrestin 1 . During the investigation of the genes modulated by these cascades, it was discovered that of the genes specifically modulated by $\beta$-arrestins, $\sim 70 \%$ control gene transcription and protein synthesis, suggesting a significant role of this signaling wave in the long-term effects of $\mathrm{CB}_{1} \mathrm{R}$ activation. Remarkably, VEGFA, GH1, and ADAMTS1, genes that have been involved in cancer growth and neurodegeneration, are among the genes specifically regulated by $\beta$-arrestins (Delgado-Peraza et al., 2016).

Biased $\mathrm{CB}_{1} \mathrm{Rs}$ were also generated by mutations in the highly conserved Asp-Arg-Tyr (DRY) motif (Gyombolai et al., 2015). Either G-protein or $\beta$-arrestin 1/2-biased receptors were reported based on $\mathrm{G}_{\mathrm{o}}$ and $\beta$-arrestin $1 / 2$ BRET responses in Chinese hamster ovary cells. Inhibition of forskolin-induced cAMP accumulation in Chinese hamster ovary cells and increased pERK levels by the AAY mutant suggested a $\beta$-arrestin bias, which supports the idea that mutations at the $\mathrm{CB}_{1} \mathrm{R}$ intracellular loop 2 comprising the $\beta$-arrestin binding site can significantly modify receptor signaling (Gyombolai et al., 2015).

\section{Future Directions}

Over the last 5 years, we have witnessed a significant increase in our knowledge of the mechanisms and signaling cascades controlled by the multifunctional scaffold protein, $\beta$-arrestin, downstream from the $\mathrm{CB}_{1} \mathrm{R}$. In general, mounting evidence indicates that signaling cascades can be directly regulated by $\beta$-arrestin 1 , whereas $\mathrm{CB}_{1} \mathrm{R}$ endocytosis is regulated by $\beta$-arrestin 2 (Ahn et al., 2013; Gyombolai et al., 2013; Srivastava et al., 2015; Delgado-Peraza et al., 2016). These signaling cascades control specific gene transcription, providing an initial glimpse to the physiologic roles of $\beta$-arrestin-mediated signaling. Recent advances on transcriptomics, signaling screenings, and computational analysis have allowed the assessment of $\beta$-arrestin-mediated signaling on a global scale. For example, $\beta$-arrestin-mediated transcriptomic signatures were shown to be conserved in vivo and in vitro, sometimes across multiple tissues, suggesting conserved biologic responses (Gesty-Palmer et al., 2013; Maudsley et al., 2015). Among them, there is a common core of biologic functions regulated by $\beta$-arrestins, such as cell growth and survival, as reported for the $\mathrm{CB}_{1} \mathrm{R}$ (DelgadoPeraza et al., 2016), and these core molecular targets could potentially mediate some of the long-term effects of CB1R activation. It is interesting to note that some of the genes specifically regulated by $\beta$-arrestins downstream from the $\mathrm{CB}_{1}$ receptor control vasculature growth and prosurvival aspects of the ER-stress response, potentially explaining some of the therapeutic effects of the cannabinoid system and the effect of long-term exposure to cannabis.

Bias analysis by systematic investigation of ligands utilizing multiple readouts followed by careful quantification by bias factor analysis should provide a better understanding of the multiple biologic effects of GPCR activation and the specific effect of ligands (Stahl et al., 2015). This information should be obtained from physiologically relevant cells where receptor and signaling molecule expression levels are known and within physiologic levels to help profile novel therapeutic agents and unravel the pharmacology of the receptor (Kenakin and Christopoulos, 2013; Kenakin, 2014; Masuho et al., 2015; Maudsley et al., 2015).

Fundamental questions still remain, however. For example, why would the same cascades (e.g., ERK, CREB) be activated by different pathways ( $\mathrm{G}$ proteins and $\beta$-arrestins) but with 
different spatiotemporal profiles? How do cells integrate these responses, and how conserved or relevant are these effects in vivo? Importantly, what are the physiologic roles of $\beta$-arrestin-mediated signaling, and can we specifically target these cascades for therapeutic goals? These are some of the fundamental questions the field will try to address in the coming years.

\section{Acknowledgments}

The authors offer apologies to all the authors whose work was not included in this review and thank Dr. Debra Kendall for feedback and continuous scientific discussions.

\section{Authorship Contributions}

Wrote or contributed to the writing of the manuscript: NoguerasOrtiz, Yudowski.

\section{References}

Ahn KH, Mahmoud MM, and Kendall DA (2012) Allosteric modulator ORG27569 induces CB1 cannabinoid receptor high affinity agonist binding state, receptor internalization, and $\mathrm{Gi}$ protein-independent ERK1/2 kinase activation. J Biol Chem 287:12070-12082.

Ahn KH, Mahmoud MM, Shim J-Y, and Kendall DA (2013) Distinct roles of $\beta$-arrestin 1 and $\beta$-arrestin 2 in ORG27569-induced biased signaling and internalization of the cannabinoid receptor 1 (CB1). J Biol Chem 288:9790-9800.

Allen JA, Yost JM, Setola V, Chen X, Sassano MF, Chen M, Peterson S, Yadav PN Huang XP, Feng B, et al. (2011) Discovery of $\beta$-arrestin-biased dopamine D2 ligands for probing signal transduction pathways essential for antipsychotic efficacy. Proc Natl Acad Sci USA 108:18488-18493.

Ariens EJ (1954) Affinity and intrinsic activity in the theory of competitive inhibition. I. Problems and theory. Arch Int Pharmacodyn Ther 99:32-49.

Atwood BK, Lopez J, Wager-Miller J, Mackie K, and Straiker A (2011) Expression of G protein-coupled receptors and related proteins in HEK293, AtT20, BV2, and N18 cell lines as revealed by microarray analysis. BMC Genomics 12:14.

Baillie GL, Horswill JG, Anavi-Goffer S, Reggio PH, Bolognini D, Abood ME, McAllister S, Strange PG, Stephens GJ, Pertwee RG, et al. (2013) CB(1) receptor allosteric modulators display both agonist and signaling pathway specificity. $\mathrm{Mol}$ Pharmacol 83:322-338.

Benovic JL, Kühn H, Weyand I, Codina J, Caron MG, and Lefkowitz RJ (1987) Functional desensitization of the isolated beta-adrenergic receptor by the betaadrenergic receptor kinase: potential role of an analog of the retinal protein arrestin (48-kDa protein). Proc Natl Acad Sci USA 84:8879-8882.

Bohn LM, Gainetdinov RR, Lin FT, Lefkowitz RJ, and Caron MG (2000) Mu-opioid receptor desensitization by beta-arrestin-2 determines morphine tolerance but not dependence. Nature 408:720-723 Nature Publishing Group.

Bosier B, Hermans E, and Lambert D (2008) Differential modulation of AP-1- and CRE-driven transcription by cannabinoid agonists emphasizes functional selectivity at the CB1 receptor. Br J Pharmacol 155:24-33.

Bosier B, Muccioli GG, Hermans E, and Lambert DM (2010) Functionally selective cannabinoid receptor signalling: therapeutic implications and opportunities. Biochem Pharmacol 80:1-12.

Brailoiu GC, Oprea TI, Zhao P, Abood ME, and Brailoiu E (2011) Intracellular cannabinoid type 1 (CB1) receptors are activated by anandamide. $J$ Biol Chem $\mathbf{2 8 6}$ : 29166-29174.

Breivogel CS, Lambert JM, Gerfin S, Huffman JW, and Razdan RK (2008) Sensitivity to delta9-tetrahydrocannabinol is selectively enhanced in beta-arrestin2 -/- mice Behav Pharmacol 19:298-307.

Breivogel CS and Vaghela MS (2015) The effects of beta-arrestin1 deletion on acute cannabinoid activity, brain cannabinoid receptors and tolerance to cannabinoids in mice. J Recept Signal Transduct Res 35:98-106.

Brust TF, Hayes MP, Roman DL, Burris KD, and Watts VJ (2015) Bias analyses of preclinical and clinical D2 dopamine ligands: studies with immediate and complex signaling pathways. J Pharmacol Exp Ther 352:480-493.

Butcher AJ, Prihandoko R, Kong KC, McWilliams P, Edwards JM, Bottrill A, Mistry $\mathrm{S}$, and Tobin AB (2011) Differential G-protein-coupled receptor phosphorylation provides evidence for a signaling bar code. J Biol Chem 286:11506-11518.

Castillo PE, Younts TJ, Chávez AE, and Hashimotodani Y (2012) Endocannabinoid signaling and synaptic function. Neuron 76:70-81.

Daigle TL, Kearn CS, and Mackie K (2008) Rapid CB1 cannabinoid receptor desensitization defines the time course of ERK1/2 MAP kinase signaling. Neuropharmacology 54:36-44.

Delgado-Peraza F, Ahn KH, Nogueras-Ortiz C, Mungrue IN, Mackie K, Kendall DA and Yudowski GA (2016) Mechanisms of biased $\beta$-arrestin-sediated signaling downstream from the cannabinoid 1 receptor. Mol Pharmacol 89:618-629.

DeWire SM, Ahn S, Lefkowitz RJ, and Shenoy SK (2007) Beta-arrestins and cell signaling. Annu Rev Physiol 69:483-510.

Drake MT, Violin JD, Whalen EJ, Wisler JW, Shenoy SK, and Lefkowitz RJ (2008) Beta-arrestin-biased agonism at the beta2-adrenergic receptor. J Biol Chem 283: $5669-5676$

Flores-Otero J, Ahn KH, Delgado-Peraza F, Mackie K, Kendall DA, and Yudowski GA (2014) Ligand-specific endocytic dwell times control functional selectivity of the cannabinoid receptor 1. Nat Commun 5:4589.
Gainetdinov RR, Premont RT, Bohn LM, Lefkowitz RJ, and Caron MG (2004) Desensitization of $\mathrm{G}$ protein-coupled receptors and neuronal functions. Annu Rev Neurosci 27:107-144.

Galandrin S, Oligny-Longpré G, and Bouvier M (2007) The evasive nature of drug efficacy: implications for drug discovery. Trends Pharmacol Sci 28:423-430.

Gesty-Palmer D, Yuan L, Martin B, Wood WH, III, Lee M-H, Janech MG, Tsoi LC Zheng WJ, Luttrell LM, and Maudsley S (2013) $\beta$-arrestin-selective G proteincoupled receptor agonists engender unique biological efficacy in vivo. Mol Endocrinol 27:296-314 Endocrine Society Chevy Chase, MD.

Glass M and Northup JK (1999) Agonist selective regulation of G proteins by cannabinoid $\mathrm{CB}(1)$ and $\mathrm{CB}(2)$ receptors. Mol Pharmacol 56:1362-1369.

Goodman OB, Jr, Krupnick JG, Santini F, Gurevich VV, Penn RB, Gagnon AW, Keen $\mathrm{JH}$, and Benovic JL (1996) $\beta$-arrestin acts as a clathrin adaptor in endocytosis of the $\beta 2$-adrenergic receptor. Nature 383:447-450.

Gurevich VV and Gurevich EV (2004) The molecular acrobatics of arrestin activation. Trends Pharmacol Sci 25:105-111.

Gurevich VV and Gurevich EV (2006) Arrestins: ubiquitous regulators of cellular signaling pathways. Genome Biol 7:236.

Gyombolai P, Boros E, Hunyady L, and Turu G (2013) Differential $\beta$-arrestin2 requirements for constitutive and agonist-induced internalization of the CB1 cannabinoid receptor. $\mathrm{Mol}$ Cell Endocrinol 372:116-127.

Gyombolai P, Tóth AD, Tímár D, Turu G, and Hunyady L (2015) Mutations in the 'DRY' motif of the CB1 cannabinoid receptor result in biased receptor variants. J Mol Endocrinol 54:75-89.

Herkenham M, Lynn AB, Johnson MR, Melvin LS, de Costa BR, and Rice KC (1991) Characterization and localization of cannabinoid receptors in rat brain: a quantitative in vitro autoradiographic study. J Neurosci 11:563-583.

Howlett AC (2005) Cannabinoid receptor signaling. Handb Exp Pharmacol 4:53-79. Howlett AC, Barth F, Bonner TI, Cabral G, Casellas P, Devane WA, Felder CC, Herkenham M, Mackie K, Martin BR, Mechoulam R, and Pertwee RG (2002) International Union of Pharmacology. XXVII. Classification of cannabinoid receptors. Pharmacol Rev 54:161-202

Howlett AC, Bidaut-Russell M, Devane WA, Melvin LS, Johnson MR, and Herkenham M (1990) The cannabinoid receptor: biochemical, anatomical and behavioral characterization. Trends Neurosci 13:420-423.

Howlett AC, Breivogel CS, Childers SR, Deadwyler SA, Hampson RE, and Porrino LJ (2004) Cannabinoid physiology and pharmacology: 30 years of progress. Neuropharmacology 47 (Suppl 1):345-358.

Jin W, Brown S, Roche JP, Hsieh C, Celver JP, Kovoor A, Chavkin C, and Mackie K (1999) Distinct domains of the CB1 cannabinoid receptor mediate desensitization and internalization. $J$ Neurosci 19:3773-3780

Johnston JM and Filizola M (2014) Beyond standard molecular dynamics: in vestigating the molecular mechanisms of $\mathrm{G}$ protein-coupled receptors with enhanced molecular dynamics methods. Adv Exp Med Biol 796:95-125.

Kang Y, Zhou XE, Gao X, He Y, Liu W, Ishchenko A, Barty A, White TA, Yefanov O, Han GW, et al. (2015) Crystal structure of rhodopsin bound to arrestin by femtosecond X-ray laser. Nature 523:561-567.

Katritch V, Cherezov V, and Stevens RC (2013) Structure-function of the G proteincoupled receptor superfamily. Annu Rev Pharmacol Toxicol 53:531-556.

Kenakin T (2011) Functional selectivity and biased receptor signaling. J Pharmacol Exp Ther 336:296-302.

Kenakin T (2004) Principles: receptor theory in pharmacology. Trends Pharmacol Sci 25:186-192.

Kenakin T (2014) Quantifying biased $\beta$-arrestin signaling. Handbook Exp Pharmacol 219:57-83.

Kenakin T and Christopoulos A (2013) Signalling bias in new drug discovery: detection, quantification and therapeutic impact. Nat Rev Drug Discov 12:205-216.

Kouznetsova M, Kelley B, Shen M, and Thayer SA (2002) Desensitization of cannabinoid-mediated presynaptic inhibition of neurotransmission between rat hippocampal neurons in culture. Mol Pharmacol 61:477-485.

Laporte SA, Oakley RH, Zhang J, Holt JA, Ferguson SSG, Caron MG, and Barak LS (1999) The beta2-adrenergic receptor/betaarrestin complex recruits the clathrin adaptor AP-2 during endocytosis. Proc Natl Acad Sci USA 96:3712-3717.

Laprairie RB, Bagher AM, Kelly MEM, and Denovan-Wright EM (2016) Biased type 1 cannabinoid receptor signaling influences neuronal viability in a cell culture model of Huntington disease. Mol Pharmacol 89:364-375.

Laprairie RB, Bagher AM, Kelly MEM, Dupré DJ, and Denovan-Wright EM (2014) Type 1 cannabinoid receptor ligands display functional selectivity in a cell culture model of striatal medium spiny projection neurons. J Biol Chem 289:24845-24862.

Liggett SB (2011) Phosphorylation barcoding as a mechanism of directing GPCR signaling. Sci Signal 4:pe36.

Liu JJ, Horst R, Katritch V, Stevens RC, and Wüthrich K (2012) Biased signaling pathways in $\beta 2$-adrenergic receptor characterized by 19F-NMR. Science 335:1106-1110.

Lohse M, Benovic J, Codina J, Caron M, and Lefkowitz R (1990) beta-Arrestin: a protein that regulates beta-adrenergic receptor function. Science 248:1547-1550.

Lohse MJ and Calebiro D (2013) Cell biology: Receptor signals come in waves. Nature 495: $457-458$.

Luttrell LM (2014) Minireview. More than just a hammer: ligand "bias" and pharmaceutical discovery. Mol Endocrinol 28:281-294.

Luttrell LM and Gesty-Palmer D (2010) Beyond desensitization: physiological relevance of arrestin-dependent signaling. Pharmacol Rev 62:305-330.

Lutz B, Marsicano G, Maldonado R, and Hillard CJ (2015) The endocannabinoid system in guarding against fear, anxiety and stress. Nat Rev Neurosci 16:705-718 Nature Publishing Group.

Mackie K (2006) Cannabinoid receptors as therapeutic targets. Annu Rev Pharmacol Toxicol 46:101-122.

Mackie K (2008) Cannabinoid receptors: where they are and what they do. $J$ Neuroendocrinol 20(Suppl 1):10-14.

Mahavadi S, Sriwai W, Huang J, Grider JR, and Murthy KS (2014) Inhibitory signaling by CB1 receptors in smooth muscle mediated by GRK5/ $\beta$-arrestin activation of ERK1/2 and Src kinase. Am J Physiol Gastrointest Liver Physiol 306:G535-G545. 
Mailman RB (2007) GPCR functional selectivity has therapeutic impact. Trends Pharmacol Sci 28:390-396.

Marsicano G and Kuner R (2008) Anatomical distribution of receptors, ligands and enzymes in the brain and in the spinal cord: circuitries and neurochemistry, in Cannabinoids and the Brain (Köfalvi A, ed) pp 161-201, Springer US, Boston, MA

Masuho I, Ostrovskaya O, Kramer GM, Jones CD, Xie K, and Martemyanov KA (2015) Distinct profiles of functional discrimination among G proteins determine the actions of G protein-coupled receptors. Sci Signal 8:ra123-ra123.

Maudsley S, Martin B, Gesty-Palmer D, Cheung H, Johnson C, Patel S, Becker KG, Wood WH, 3rd, Zhang Y, Lehrmann E, et al. (2015) Delineation of a conserved arrestin-biased signaling repertoire in vivo. Mol Pharmacol 87:706-717.

Maudsley S, Siddiqui S, and Martin B (2013) Systems analysis of arrestin pathway functions. Prog Mol Biol Transl Sci 118:431-467 Elsevier Inc.

Morgan DJ, Davis BJ, Kearn CS, Marcus D, Cook AJ, Wager-Miller J, Straiker A Myoga MH, Karduck J, Leishman E, et al. (2014) Mutation of putative GRK phosphorylation sites in the cannabinoid receptor 1 (CB1R) confers resistance to cannabinoid tolerance and hypersensitivity to cannabinoids in mice. J Neurosci $\mathbf{3 4}$ 5152-5163.

Nguyen PT, Schmid CL, Raehal KM, Selley DE, Bohn LM, and Sim-Selley LJ (2012) $\beta$-arrestin2 regulates cannabinoid CB1 receptor signaling and adaptation in a central nervous system region-dependent manner. Biol Psychiatry 71:714-724.

Nobles KN, Xiao K, Ahn S, Shukla AK, Lam CM, Rajagopal S, Strachan RT, Huang TY, Bressler EA, Hara MR, et al. (2011) Distinct phosphorylation sites on the $\beta(2)$ adrenergic receptor establish a barcode that encodes differential functions of $\beta$-arrestin. Sci Signal 4:ra51.

Pfister C, Chabre M, Plouet J, Tuyen VV, De Kozak Y, Faure JP, and Kühn H (1985) Retinal $\mathrm{S}$ antigen identified as the $48 \mathrm{~K}$ protein regulating light-dependent phosphodiesterase in rods. Science 228:891-893.

Premont RT and Gainetdinov RR (2007) Physiological roles of G protein-coupled receptor kinases and arrestins. Annu Rev Physiol 69:511-534.

Prihandoko R, Alvarez-Curto E, Hudson BD, Butcher AJ, Ulven T, Miller AM, Tobin $\mathrm{AB}$, and Milligan G (2016) Distinct phosphorylation clusters determine the signaling outcome of free fatty acid receptor $4 / \mathrm{g}$ protein-coupled receptor 120 . Mol Pharmacol 89:505-520.

Rozenfeld R and Devi LA (2008) Regulation of CB1 cannabinoid receptor trafficking by the adaptor protein AP-3. FASEB $J$ 22:2311-2322.

Schmid CL and Bohn LM (2009) Physiological and pharmacological implications of beta-arrestin regulation. Pharmacol Ther 121:285-293.
Shenoy SK and Lefkowitz RJ (2011) $\beta$-Arrestin-mediated receptor trafficking and signal transduction. Trends Pharmacol Sci 32:521-533.

Shukla AK, Singh G, and Ghosh E (2014a) Emerging structural insights into biased GPCR signaling. Trends Biochem Sci 39:594-602.

Shukla AK, Westfield GH, Xiao K, Reis RI, Huang L-Y, Tripathi-Shukla P, Qian J, Li S, Blanc A, Oleskie AN, et al. (2014b) Visualization of arrestin recruitment by a G-protein-coupled receptor. Nature 512:218-222 Nature Publishing Group.

Srivastava A, Gupta B, Gupta C, and Shukla AK (2015) Emerging functional divergence of $\beta$-arrestin isoforms in GPCR function. Trends Endocrinol Metab 26: 628-642.

Stahl EL, Zhou L, Ehlert FJ, and Bohn LM (2015) A novel method for analyzing extremely biased agonism at $\mathrm{G}$ protein-coupled receptors. Mol Pharmacol 87: 866-877.

Straiker A, Wager-Miller J, Hutchens J, and Mackie K (2012) Differential signalling in human cannabinoid CB1 receptors and their splice variants in autaptic hippocampal neurones. Br J Pharmacol 165:2660-2671.

Tzingounis AV, von Zastrow M, and Yudowski GA (2010) Beta-blocker drugs mediate calcium signaling in native central nervous system neurons by beta-arrestin-biased agonism. Proc Natl Acad Sci USA 107:21028-21033.

Urban JD, Clarke WP, von Zastrow M, Nichols DE, Kobilka B, Weinstein H, Javitch JA, Roth BL, Christopoulos A, Sexton PM, et al. (2007) Functional selectivity and classical concepts of quantitative pharmacology. J Pharmacol Exp Ther 320: $1-13$.

Urs NM, Nicholls PJ, and Caron MG (2014) Integrated approaches to understanding antipsychotic drug action at GPCRs. Curr Opin Cell Biol 27:56-62.

Varga EV, Georgieva T, Tumati S, Alves I, Salamon Z, Tollin G, Yamamura HI, and Roeske WR (2008) Functional selectivity in cannabinoid signaling. Curr Mol Pharmacol 1:273-284.

Warne T, Serrano-Vega MJ, Baker JG, Moukhametzianov R, Edwards PC, Henderson R, Leslie AGW, Tate CG, and Schertler GFX (2008) Structure of a beta1adrenergic G-protein-coupled receptor. Nature 454:486-491.

Whalen EJ, Rajagopal S, and Lefkowitz RJ (2011) Therapeutic potential of $\beta$-arrestin- and G protein-biased agonists. Trends Mol Med 17:126-139.

Address correspondence to: Guillermo A. Yudowski, Institute of Neurobiology, 201 Calle Norzagaray, San Juan, Puerto Rico 00901. Guillermo. yudowski@upr.edu 